\title{
A dinâmica do Esporte olímpico do século XIX ao XXI
}

Kátia RUBIO*
*Escola de Educação Física e Esporte, Universidade de São Paulo.

\section{Resumo}

A sociedade contemporânea tem na velocidade de transformação de conceitos e padrões e no dinamismo suas principais marcas. 0 reconhecimento desse fenômeno por pensadores de diferentes correntes teóricas e mesmo os cidadãos comuns que se prestam a observar seu entorno são capazes de notar rápidas e estruturais alterações sociais. 0 esporte é um dos maiores fenômenos culturais da sociedade contemporânea e em virtude disso, suas características em muito se assemelham com a do contexto no qual se insere. 0 presente texto buscou estreitar as relações entre esporte e sociedade, reconhecendo seus pontos comuns e propondo maneiras de se olhar para o fenômeno esportivo na contemporaneidade. Sem pretensões de aqui encerrar o assunto e questionando a possibilidade disso efetivamente acontecer, notou-se que haverá sempre grande dificuldade na compreensão dos fenômenos esportivos modernos, uma vez que a intensa velocidade de transformação dificulta análises profundas. No entanto é preciso reconhecer a importância do pensar o esporte inserido na sociedade, para que as ações envolvendo 0 esporte não sejam carregadas de elementos alienantes e pouco relevantes aos que o praticam.

Unitermos: Esporte; Dinamismo; Século XX; Contemporaneidade.

\section{Introdução}

Foi durante o século XIX que as atençóes de estudiosos se voltaram para a Grécia Antiga buscando a gênese de fenômenos ocidentais contemporâneos. No bojo dessas investigaçôes estavam as origens das atividades atléticas, dos Jogos Públicos e mais especificamente dos Jogos Olímpicos (Cabral, 2004; Christopoulos, 2003; Diem, 1966, Durantez, 1979; Machado, 2006, 2009; Munguia, 1992; Vernant, 1990; Yalouris, 2003).

O Movimento Olímpico contemporâneo, tendo como principal ideólogo Pierre de Freddy, conhecido pelo título de Barão de Coubertin, baseou-se nos rituais da Grécia antiga para criar aquele que seria o maior fenômeno sociocultural contemporâneo. Educador, pensador e historiador, quando se empenhou na reorganização dos Jogos Olímpicos almejava valorizar os aspectos pedagógicos do esporte mais do que assistir à conquista de marcas e quebra de recordes. Sua preocupação fundamental era valorizar a competição leal e sadia, o culto ao corpo e à atividade física.

Embora de origem aristocrática Coubertin resistia à ideia e a prática de perpetuar um modelo político social que havia levado a França a três monarquias, dois impérios e três repúblicas em menos de 100 anos. Por essa razão definia-se como um republicano e embora desacreditasse da política desejava promover ações que levassem à transformação de uma sociedade que lhe parecia enferma.

Nesse contexto começou a frequentar a École Supérieure des Sciences Politiques na qual teve contato com a pessoa e a obra de Hipólito Taine e com um núcleo anglófilo que buscava compreender a dinâmica cultural inglesa capaz de proporcionar uma estabilidade social que faltava à França. De acordo com TAVAres (2003) duas características da sociedade inglesa interessavam a Coubertin e iriam influenciar sobremaneira sua obra e suas açōes: uma delas era o 'espírito de associação' da sociedade inglesa "corporificado nas associaçōes privadas de patronato das mais diversas causas" (p.40); o segundo foi o sistema educacional inglês, "inclusive as atividades esportivas nas escolas que Taine discute sublinhando seu valor como uma preparação para a vida numa sociedade democrática” (p.40).

Mas, sobretudo as obras Notes sur l'Anglaterre de Hippolyte Taine e Tom Brown's Schooldays de Thomas Hughes iriam provocar profunda identificação de Coubertin com o sistema educacional e esportivo ingleses. Hughes foi aluno de Thomas Arnold na escola de "Rugby", marco da institucionalização 
do esporte nas escolas inglesas, e na obra Tom Brown's relatou de forma romanesca e apaixonada o cotidiano e as preocupações de uma pedagogia pelo esporte. A fundamentação dessa pedagogia se assentava na responsabilidade e na hierarquia. A responsabilidade estava associada ao uso da liberdade e do cumprimento de normas e tradiçōes que entre, outras açôes, refletia-se no uso do tempo ocioso. A hierarquia demandava a compreensão e aceitação de uma 'ordem natural' imposta pelos veteranos, por aqueles que primeiro chegaram à instituição impondo a perpetuação de uma cultura que deveria ser reproduzida pelos mais novos (RuBIO, 2002a).

Embora Coubertin encontrasse em Taine o eco necessário para a reflexão sobre um modelo pedagógico é em Frédéric Le Play que a reforma social por meio de uma pedagogia esportiva encontrará seu porto seguro. Organizador da Société d'Économie Sociale e da Unions de la Paix Sociale, Le Play sociólogo e filósofo da segunda metade do século XIX exerceu grande influência sobre Coubertin que iria afirmar em seus escritos no final da vida que "Le Play foi, juntamente com Arnold, o mestre a quem dedico minha gratidão no momento em que o fim se aproxima. A esses dois homens eu devo mais do que eu posso dizer" (MANGAN, 1986, p.83).

Coubertin começou a se preocupar em desenvolver um modelo de reforma social por meio da educação e do esporte em uma perspectiva internacionalista depois de obter pouco sucesso com programas de caráter educacional em seu país, a França. MACALOON (1984) aponta que durante os idos de 1880 visitou inúmeras escolas inglesas, uma verdadeira peregrinação, em busca de referência para seu projeto esportivo-pedagógico, deslocando, entretanto esse micro sistema - a educação - do macro sistema - a sociedade - no qual ele estava inserido e situado. Não satisfeito com isso, em 1889, partiu para os Estados Unidos para conhecer de perto o modelo americano emergente e distinto do inglês, agora não mais na condição de observador, mas como comissário oficial do governo francês ligado ao ministério da educação. Em quatro meses visitou escolas e universidades de Chicago e New York até New Orleans e Flórida. Nessa oportunidade Coubertin mostrou-se surpreso com os 'sentimentos democráticos do catolicismo americano' que separava igreja do Estado e tolerava a liberdade de culto, fato menos comum na Inglaterra. Talvez essa questão tenha lhe chamado tanta atenção em virtude da resistência que os países de cultura puritana ofereciam à ideia dos jogos Olímpicos, relacionando-os com uma festa pagã, extinta pelo imperador Teodósio, um católico fervoroso, a pedido do bispo de Milão, San Ambrosio, no ano de 394.

Foi, sobretudo, o renascimento do interesse pelos estudos clássicos, fazendo reviver na intelectualidade de então a fascinação que a cultura helênica exercia sobre a cultura europeia, além das descobertas de sítios arqueológicos que permitiam desvendar acontecimentos relacionados aos Jogos Olímpicos da Antiguidade, que levou Pierre de Coubertin a tomar para si a tarefa de organizar uma instituição de caráter internacional com a finalidade de cuidar daquilo que seria uma atividade capaz de transformar a sociedade daquele momento: o esporte (RUBIo, 2001, 2002b).

TAVARES (2003) aponta que o estabelecimento do Movimento Olímpico nos idos de 1894 coincide com a criação e proliferação de um amplo espectro de organizações de cunho internacionalista, cujo principal objetivo era a promoção da paz. Isso porque, embora durante o século XIX tivesse ocorrido um grande desenvolvimento das ciências humanas e da produção de ideias, os conflitos ainda eram resolvidos de forma brutal por meio da guerra. As organizaçôes internacionalistas buscavam a resolução de conflitos, tanto de ordem interna como externa, pelo uso da razão e das leis, e não pelas armas. Dentro dessa lógica a competição esportiva era uma forma racionalizada de conflito, sem o uso da violência.

O projeto de restauração dos Jogos Olímpicos como na Grécia Helênica foi apresentado em 25 de novembro de 1892 quando da ocasião do $5^{\circ}$ aniversário da União das Sociedades Francesas de Esportes Atléticos, que teve como paraninfo o Barão de Coubertin. Naquela ocasião ele manifestaria seu desejo e intençōes com relação os Jogos: "É preciso internacionalizar o esporte. É necessário organizar novos Jogos Olímpicos" (López, 1992, p.21).

A tarefa audaciosa de promover uma competição esportiva de âmbito internacional, espelhada nos Jogos Olímpicos gregos, com caráter educativo e permanente demandava a criação de uma instituição que desse o suporte humano e material para a realização de tal empreitada. E assim, em junho de 1894, na Sorbonne, diante de uma plateia que reunia aproximadamente duas mil pessoas, das quais 79 representavam sociedades esportivas e universidades de 13 naçōes, teve início o congresso esportivocultural em Paris, no qual Coubertin apresentou a proposta de recriação dos Jogos Olímpicos.

Inicialmente o Barão intentava realizar a primeira edição dos Jogos Olímpicos na capital francesa em 1900, como parte das comemoraçóes da virada do século que ocorreria em seis anos. Entretanto, 
diferentemente do que havia sugerido o proponente, a competição foi antecipada para o ano de 1896 , para Atenas, como uma deferência aos criadores dos jogos originais (RuBIO, 2002a).

Algumas particularidades marcaram a criação do Comitê Olímpico Internacional e sua dinâmica ao longo do século XX. Constituído por representantes de várias nacionalidades indicados pelos participantes do encontro da Sorbonne, o COI tinha como missão e intenção a organização dos Jogos Olímpicos bem como a normatização das modalidades disputadas, muitas delas recém-criadas e sem um corpo de regras universalizadas. A ideia inicial, e que posteriormente foi perpetuada, era da celebração de uma competição de caráter internacional, com realização quadrienal, cujos participantes estariam vinculados a representações nacionais. Subjacente a essa proposta, lembra TAVAres (2003, p.64), estava a ideia e o princípio de uma organização não ideológica, destinada a promover uma idéia, se organizar em torno de uma elite e servir a humanidade em regime de total independência de correntes políticas e de governos nacionais.

A proposta de criação da instituição nessas bases guardava preocupaçôes com a isenção, autonomia e independência de um movimento que se propunha internacional, apolítico e apartidário. Como decorrência dessa perspectiva Coubertin idealizou o Movimento Olímpico sustentado na força dos comitês olímpicos nacionais, mas principalmente na cooptação e atuação dos membros do Comitê.

Conforme já mencionado os membros do Comitê Olímpico Internacional são indicados, desde sua constituição, pelos membros já participantes, ou seja, o regime que sustenta a organização olímpica não está pautado em uma concepção democrática. TAVAREs (2003) enfatiza que Coubertin se baseou no princípio da representatividade reversa dos membros do COI como forma de garantir a independência de sua organização.

Embora reconhecida como defeituosa e limitada seu idealizador acreditava que a dinâmica impressa na instituição garantiria sua estabilidade e defende essa posição com o seguinte argumento:

Nós não somos eleitos. Não somos auto-recrutados, e nossos mandatos são limitados. Existe qualquer outra coisa que pudesse irritar mais a opiniāo pública? O público tem visto de maneira crescente o princípio da eleição se expandir, gradualmente, colocando todas as instituiçôes sob seu domínio. Em nosso caso, estamos infringindo essa regra geral, uma coisa difícil de tolerar, não é mesmo? Bem, nós temos muito prazer em tomar a responsabilidade por esta irregularidade e não estamos nem ao menos preocupados com ela (MüLLER, 2000, p.587-9).

A prática de indicação pelo próprio Comitê persiste até os dias atuais e seus membros são considerados embaixadores dos ideais olimpicos em seus respectivos países e não delegados de suas naçôes junto ao Comitê, numa tentativa de destituir aqueles que lidam com o esporte de qualquer relação com manobras políticas (SAGRAVE, 1988). Isso vem representar um paradoxo uma vez que embora não haja representação nacional dentro da estrutura burocrática do COI, a um atleta só é permitido participar de uma edição de Jogos Olímpicos desde que tenha os índices necessários, obtido em situações em que ele tenha representado seu país em eventos internacionais. Ou seja, é vetada a participação independente de qualquer pessoa, mesmo habilidosa, sem que ela defenda as cores de uma bandeira nacional.

$O$ receio de lidar com conflitos internos e o ceticismo com a democracia levou Coubertin a estruturar e organizar o COI como uma instituição unipartidária, em um modelo próximo ao oligárquico, tendo como documento norteador de sua prática a Carta Olímpica, elaborada pelo fundador do movimento olímpico em aproximadamente 1898 (VALENTE, 1999).

Regidos desde então por princípios fundamentais contidos na Carta Olímpica, os Jogos Olímpicos pautaram-se por um conjunto de valores que são a referência fundamental do Movimento Olímpico até os dias atuais.

De acordo com TaVAres (1999, p.15) os Jogos Olímpicos eram para seu reinventor a institucionalização de uma concepção de práticas de atividades físicas "que transformava o esporte em um empreendimento educativo, moral e social, destinado a produzir reflexos no plano dos indivíduos, das sociedades e das nações" - concepção que expressava a formação humanista e eclética de Coubertin. E, é justamente o ecletismo uma das chaves para compreender a lógica interna do "corpus" de valores do Olimpismo, uma vez que a definição contida nos Princípios Fundamentais da Carta Olímpica (International Olympic Committee, 2001) é pouco precisa - ou em última análise, como afirma DaCosta (1999) uma filosofia em processo durante o tempo de vida de Coubertin - o que tem levado estudiosos do tema a discussões extensas e inconclusivas (Grupe, 1992; LenK, 1976; SAGrave, 1988).

Vale ressaltar que o termo Olimpismo refere-se ao conjunto de valores pedagógicos e filosóficos do Movimento Olímpico, e não aos aspectos formais e/ou burocráticos que sustentam a instituição e o fenômeno olímpico. 
As modernas Olimpíadas, ou seja, o período em que ocorrem as ediçōes dos Jogos Olímpicos, dividem-se em Jogos de inverno e de verão, ocorrem de quatro em quatro anos, como na Antiguidade, alternando-se a cada dois anos entre os Jogos de Verão e os de Inverno. Diferentemente da dificuldade para definição da sede ocorrida nas edições iniciais, na atualidade, a realização das competiçôes é disputada por grandes metrópoles dos cinco continentes, em um processo que demanda alguns anos. O crescimento da importância do evento pode ser observado nos números entre Grécia em 1896 e Pequim em 2008. As modalidades saltaram de nove para 28. Os países participantes passaram de 13 para 204. De 250 atletas homens na Grécia o total entre mulheres e homens em Pequim chegou a 10.500. A evolução dos números é um bom indicador de que na atualidade os Jogos Olímpicos adquiriram a importância e o prestígio de que desfrutavam na Grécia Helênica, embora as razões para isso sejam bastante distintas.

Para os gregos, os Jogos representavam um momento de trégua nas guerras e conflitos de qualquer ordem para que competidores e espectadores pudessem chegar a Olímpia. Ao longo desses 104 anos de competições os Jogos Olímpicos da Era Moderna já sofreram interrupção por causa das duas Grandes Guerras e boicotes promovidos por Estados Unidos e União Soviética na década de 80 , indicando que o Movimento Olímpico não está alheio às questões sociais e políticas do mundo contemporâneo como desejava Pierre de Coubertin. Essas são algumas das marcas da modernidade nos Jogos Olímpicos (Rubio, 2006).

\section{Esporte e sociedade no breve século XX}

Conforme nos lembra SALVADOR (2004) as aproximaçôes entre as práticas da Antiguidade e as atuais recorrem ao romantismo e ao simbolismo. São locuções esportivas que atribuem aos campos e às quadras o "status" de "templos sagrados", atribuem aos atletas o "status" de "heróis", e às vitórias a condição de "feitos épicos". É a mesma lógica para nomear os torcedores violentos que frequentam as arenas esportivas de "vândalos" ou "bárbaros", nesse caso fazendo alusões negativas ao comportamento agressivo de determinados povos antigos. Ainda que o imaginário heróico prevaleça no esporte atual (RUBIO, 2001), sua estrutura e funcionamento estão fundamentados em uma lógica ditada por uma sociedade que tem como referência a produção e, portanto é objetivo, técnico, quantitativo e associado aos valores e descobertas científicas. $\mathrm{E}$ por isso não pode ser comparado às práticas atléticas da Antiguidade quanto a sociedade era então pautada em outro modo de produção.

Mesmo quando não competitiva a atividade esportiva contemporânea carrega elementos de funcionalidade, em detrimento da transcendência e da relação divina que se reconhecia na Antiguidade. A prática da atividade física e do jogo se desenvolve por razões estéticas, busca de relaxamento, compensação de uma vida regrada e estressante ou mesmo por simples passatempo. O nome atribuído ao principal evento esportivo contemporâneo parece ser mesmo a mais forte relação entre atividades separadas por 17 séculos. Como visto, Pierre de Coubertin tinha desde o início o intento de ampliar os horizontes do esporte e dos Jogos Olímpicos e sabia que para isso seria necessária a ajuda de figuras políticas relevantes espalhadas pelo mundo. Criou, então, uma competição que já nasceu com história e que já possuía tradição, condição imprescindível a um evento como os Jogos Olímpicos, conforme aponta HobSBAWN (2002) a respeito da origem e invenção das tradições. Esse processo garantiu maior crédito e inserção em diferentes círculos por não se tratar de um impulso, mas da retomada de uma prática com séculos de tradição. Essa tradição inventada foi mais um dos marcos do século XX.

Para autores como Hobsbawn (1995) e SeVCEnKo (2001) o Século XX não foi um espaço de 100 anos como outros até então registrados na História. As alteraçôes decorrentes do Século XX aconteceram de maneira rápida, profunda e irreversível. Não se tratou apenas da velocidade das transformaçōes acelerada, mas da intensidade e das consequências geradas por elas. Os meios de comunicação e tecnologia aplicada ao transporte encurtaram as distâncias e progressivamente anularam o tempo. As vantagens da cidade em relação ao campo foram reduzidas no que diz respeito ao acesso à cultura e entretenimento, uma vez que a informação que antes era necessariamente obtida "in loco" já podia ser enviada para praticamente qualquer ponto do planeta.

HobsBawn (1995) denomina esse período como "Era dos Extremos", destacando não apenas a 
característica de transformação drástica presente no Século XX, mas também o fato de grande parte das principais mudanças terem ocorrido entre a Primeira Guerra Mundial, iniciada em 1917 e o fim da União das Repúblicas Socialistas Soviéticas, em 1991. O autor considera que os principais fatos do século ocorreram em um espaço de 74 anos, o que nos dá uma noção ainda maior do adensamento do período e da quantidade de transformaçôes relevantes ocorridas em pouco espaço de tempo.

Para SevCENKo (2001) o que distinguiu o século XX em relação a qualquer outro período anterior foi uma tendência contínua e acelerada de mudança tecnológica, com efeitos multiplicativos e revolucionários sobre praticamente todos os campos da experiência humana. $\mathrm{O}$ autor ainda destaca a existência de dois períodos predominantes e diferentes em suas características. $\mathrm{O}$ primeiro deles baseado no padrão industrial, que carregava consigo as características da revolução científico-tecnológica de fins do século XIX e que permanece predominante até o final da Primeira Guerra Mundial, quando o período pós-industrial é inaugurado com o crescimento dos setores de serviços e comunicações.

O esporte no Século XX acompanhou a velocidade e o dinamismo característicos do período, sofrendo inúmeras adaptações em curtos espaços de tempo, e se adequando constantemente às novas realidades apresentadas. Mídia, dinheiro, poder político e questóes ideológicas passaram a fazer parte do esporte, que por sua vez ganhou "status" de fenômeno sociocultural (COAKLEY, 2006). O forte componente de filiação presente no esporte e descrito por McINTOSH (1975) é um dos responsáveis pelo poder da atividade, que se torna econômica e politicamente interessante por se tratar de algo vendável, capaz de atrair atenção e de ser associado a produtos, serviços, empresas e até mesmo Estados.

Os diferentes usos que se pode fazer do esporte reflete-se na característica "transideológica" descrita por HoBERMAN (1984), que conforme o período da Guerra Fria mostrou, faz com que a mesma atividade possa servir a objetivos antagônicos, demonstrando que o esporte em si não carrega necessariamente nenhum componente além de suas regras, tempos e espaços. A maneira como cada sociedade, cada Estado ou cada empresa administra essa capacidade é, sim, decisiva nos desdobramentos e consequências da atividade esportiva.

Nesse sentido, a característica de combate civilizado fez com que os blocos político-ideológicos que se formaram depois das Grandes Guerras aumentasse a importância do esporte, reforçando a simbologia da vitória na competição esportiva para outras esferas da vida social, buscando com isso o reconhecimento internacional para o sistema político e econômico como um todo.

Nesse cenário os meio de comunicação ampliaram sua influência e importância para o esporte, tornando-se seu poderoso (BETTI, 2004; HoBERMAN, 1984), sendo a responsável direto pelo seu alcance mundial, pelo vulto alcançado pela atividade e pela fácil associação com bens e produtos comercializáveis. Se nos anos 1960 se discutia a efetividade dessa relação, na atualidade não é possível pensar que um possa sobreviver sem o outro. MoraEs (2001) mostra o crescimento desse setor nos últimos 10 anos do Século XX através do número de empresas de telecomunicações, que saltou de 330 em todo o planeta para mais de 3 mil apenas nos Estados Unidos.

As complexas e intrincadas associações citadas até agora evidenciam os porquês do interesse na atividade esportiva, e mais especificamente dos Jogos Olímpicos, por parte do poder público ou da iniciativa privada (RUBIO, 2002b). A consequência óbvia dessa relação está no fato das organizações esportivas se valerem do poder que conquistaram da mesma maneira que sistemas políticos e econômicos fazem uso do esporte para obter os mais variados ganhos.

MeYNAUd (1972) sintetiza a relação do esporte no mundo atual apontando o peso político que as instituiçóes esportivas e seus dirigentes conquistaram em diferentes países, com distintos sistemas de governo. Isso porque somos de alguma forma e em diferentes níveis praticantes, espectadores ou consumidores de produtos direta ou indiretamente relacionados ao esporte e a negação disso é, no mínimo, ingenuidade.

Como apontam McNamee (2010), LASCH (2010) e Walsh e GiUlianotti (2010) ao tentarem responder o que há de errado com o esporte, é preciso observar as diferentes forças que atuam sobre o esporte no mundo contemporâneo. Isso significa considerar tantos os aspectos sociais quanto culturais onde se desenvolve tanto a prática competitiva como a participativa, fugindo de afirmações generalizantes que apontam o capitalismo como a fonte de degradação do esporte na atualidade. Para esses autores a questão central da crise que atinge o esporte está na corrupção e não em questões históricas associadas a ele como o militarismo, a educação, a exploração comercial ou o patriotismo.

Uma das condiçôes intrínsecas do esporte é o movimento, que lapidado e especializado proporciona a plástica do espetáculo esportivo. No entanto, aponta 
LASCH (2010), que o espectador, em sua passividade vegetativa afastando-se cada vez mais da do esporte como ritual, profanando-o nessa condição.

Aí talvez resida uma das principais distinçōes entre o esporte olímpico do Século XIX e do Século XXI: a transformação do atleta amador, com

\section{Considerações finais}

Diversos autores de diferentes origens têm discutido a alteração dos rumos do Olimpismo e do Movimento Olímpico, principalmente na segunda metade do século XX (Bourdieu, 1993; Brohm, 1993; Carrington, Ben, McDonald \& Hargreaves, 2005; Guttmann, 1978, 1992; Jarvie, 2006; MacClancy, 1996; Maguire, 2005; Mandell, 1986; Simons \& JenNings, 1992; Walsh \& GiulianotTi, 2007). Isso porque não só os Estados Nacionais utilizaram o esporte de maneira geral, e os Jogos Olímpicos mais especificamente, como palco para as dramatizaçôes da Guerra Fria. Além disso, a partir da década de 80, os Jogos Olímpicos foram transformados em um dos produtos mais rentáveis do planeta, afastando-os do idealismo utópico desejado por Pierre de Coubertin e colocando-os dentro da lógica de mercado que rege quase todas relações no mundo contemporâneo (BEAMISH \& RiTCHI, 2006; Coackley, 2006; Coackley \& Dunning, 2004; Morgan, 2006; Roche,1998). Essa transformação alterou radicalmente a relação do atleta com a prática esportiva, de um modelo amador para o extremo profissionalismo, e também o entendimento dos Jogos Olímpicos e do Olimpismo pela sociedade, ou seja, de um patrimônio cultural da humanidade a um bem de consumo, e em alguns casos para uso de poucos. identidade heróica, em "commoditie", um produto comercializável e substituível após o vencimento de seu prazo de validade. O esvaziamento da pregnância mítica contribui para a passividade também daqueles que no passado assistiam, e na atualidade, consomem o espetáculo esportivo.
Interesses econômicos, políticos e ideológicos por um lado, e o desenvolvimento de equipamentos e das teorias do treinamento levaram os atletas, atores do espetáculo esportivo, a observarem profundas transformações em sua atividade fim e em suas próprias identidades. Isso porque, o produto esporte não existe sem esse protagonismo, muito embora isso não possa ser considerado como uma unanimidade. A especulação que ocorre no ambiente esportivo, envolvendo negociação de contratos entre empresas, clubes, federaçōes e atletas, não difere muito do mercado de capitais de maneira geral, levando a crises e bancarrotas pouco distintas do mercado financeiro de forma geral. O que diferencia um cenário de outro é a utilização da emoção como justificativa para o esquecimento ou superação dos problemas gerados por toda essa negociata.

Se se observar com atenção talvez essa seja uma das poucas semelhanças que o esporte olímpico do século XIX guarda com o do século XXI: a emoção que a competição ainda desperta no espectador. Mas, nunca é demais alertar que também essa sensação genuína pode se tornar um simulacro (BAUDRILlard, 1991) caso as manipulações institucionais persistam sobre a produção dos resultados que deveriam ser o registro da superação.

\begin{abstract}
The dynamics of the Olympic Sport of the century XIX to the XXI

The current society have two indelible trademarks - the speed in which concepts and standards are transformed and its dynamism. The recognition if that phenomenon is being made by countless contemporary authors and even by the common citizens that observes his/hers surroundings and can easily notice how fast social and structural changes occur. Sports are a relevant element of contemporary society and because of that its aspects and characteristics are deeply connected to the social context. The dissertation that follows looks into narrowing the space between sports and society, acknowledging the common points and bringing to the table new ways of looking at the sports phenomenon in contemporary society. With no intention of ending that discussion and questioning if we will ever in fact
\end{abstract}


find an end, it's noticeable that there will always be a great deal of hard work in fully understanding the sports phenomenon in the modern world, since the speed in which everything happens makes it almost impossible to analyze things with the necessary depth. However, we must recognize how important is the study of sports in society, to the actions around it do not get taken as elements of alienation and irrelevancy to those who practice it.

UNITERMS: Sport; Contemporary society; XX Century; Dynamism.

\section{Referências}

BAUDRILLARD, J. Simulacros e simulação. Lisboa: Relógio d'Água, 1991.

BEAMISH, R.; RITCHI, I. Fastest, highest, strongest: a crititque os high-performance sport. London: Routledge, 2006. BETTI, M. A janela de vidro: esporte, televisão e educação física. 3. ed. Campinas: Papirus, 2004.

BOURDIEU, P. Deporte y clase social. In: MATERIALES de sociologia del deporte. Madrid: Las Ediciones de La Piqueta, 1993. BROHM, J.M. Las funciones ideológicas del deporte capitalista. In: MATERIALES de sociologia del deporte. Madrid: Las Ediciones de La Piqueta, 1993.

CABRAL, L.A.M. Os jogos olímpicos na Grécia Antiga. São Paulo: Odysseus, 2004.

CARRINGTON, BEN; McDONALD, I.; HARGREAVES, J. (Eds.). Marxism, cultural studies and sport. London: Routledge, 2005.

COAKLEY, J. Sports in society: issues and controversies. Champaign: Human Kinectics, 2006.

COAKLEY, J.; DUNNING, E. Handbook of sports studies. London: Sage, 2004.

CHRISTOPOULOS, G.A. The olympic games in Ancient Greece. Athens: Ekdotike Athenon, 2003.

DaCOSTA, L.P. O olimpismo e o equilíbrio do homem. In: TAVARES, O.; DaCOSTA, L.P. (Eds.). Estudos olímpicos. Rio de Janeiro: Gama Filho, 1999.

DIEN, C. Historia de los deportes. Barcelona, Luis de Caralt, 1966. v.1.

DURANTEZ, C. Olímpia e los juegos olímpicos antiguos. Madrid: Delegacion Nacional de Educacion Física e Deportes/ Comitê Olímpico Espanhol, 1979.

GRUPE, O. The sport culture and the sportization of culture: identity, legitimacy, sense and nonsense of modern sports as a cultural phenomenon. In: LANDRY, F. et al. (Eds.). Sport... the third millennium. Quebec: Les Presses de l'Université Laval, 1992.

GUTTMANN, A. History of the modern games. Champaign: University of Illinois, 1992.

From ritual to record. New York: Columbia University Press, 1978.

HOBERMAN J.M. Sport and political ideology. Austin: University of Texas Press, 1984.

HOBSBAWN, E. Era dos extremos: o breve Século XX, 1914-1991. São Paulo: Companhia das Letras, 1995.

. A produção em massa de tradiçôes: Europa, 1870 a 1914. In: HOBSBAWN, E.; RANGER, T. A invenção das tradições. Rio de Janeiro: Paz e Terra, 2002.

INTERNATIONAL OLYMPIC COMMITTEE. Olympic charter. Lausanne: International Olympic Committee, 2001. JARVIE, G. Sport, culture and society. London: Routledge, 2006.

LASCH, C. The degradation of sport. In: McNAMEE, M. (Ed.). The ethics of sports. New York: Routledge, 2010.

LENK, H. Toward a social philosophy of the Olympics: values, aims and reality of the modern Olympic Movement. In: GRAHAM, P.J.; UEBERHORST, H. (Eds.). The modern Olympics. West Point: Leisure Press, 1976.

LOPEZ, A.A. La aventura olímpica. Madrid: Campamones, 1992.

MacALOON, J.J. This great symbol. Chicago: The University of Chicago Press, 1984.

MacCLANCY, J. Sport, identity and ethnicity. Oxford: Berg, 1996.

MACHADO, R.P.T. Do mito à razão: gênese e desenvolvimento das manifestações atléticas na Grécia Antiga. 2009. Tese (Doutorado) - Escola de Educação Física e Esporte, Universidade de São Paulo, São Paulo, 2009.

. Esporte e religião no imaginário da Grécia Antiga. 2006. Dissertação (Mestrado) - Escola de Educação Física e Esporte, Universidade de São Paulo, São Paulo, 2006.

MANGAN, J.A. The games ethic and imperialism. New York: Viking Penguin, 1986.

MAGUIRE, J. Power and global sport: zones of prestige, emulation and resistance. London: Routledge, 2005.

MANDELL, R.D. Historia cultural del deporte. Barcelona: Ediciones Bellaterra, 1986. 
McINTOSH, P. C. O desporto na sociedade. Lisboa: Prelo, 1975.

McNAMEE, M. Introduction. In: McNAMEE, M. (Ed.). The ethics of sports. New York: Routledge, 2010.

MEYNAUD, J. El deporte y la política: análisis social de unas relaciones ocultas. Barcelona: Hispano Europea, 1972.

MORAES, D. O concreto e o virtual: mídia, cultura e tecnologia. Rio de Janeiro: DP\&A, 2001.

MORGAN, W.J. Why sports morally matter. London: Routledge, 2006.

MÜLLER, N. (Ed.). Olympism selected writings: Pierre de Coubertin 1863-1937. Lausanne: International Olympic Committee, 2000.

MUNGUIA, S.S. Los Juegos Olimpicos, educación, deporte, mitologia y fiestas en la Antigua Grecia. Madrid: Anaya, 1992. ROCHE, M. Sport, popular culture and identity. Aachen: Meyer\&Meyer, 1998.

RUBIO, K. Medalhistas olímpicos brasileiros: memórias, histórias e imaginário. São Paulo: Casa do Psicólogo, 2006. Questões do esporte contemporâneo: do Olimpo ao pós-olimpismo. Revista Paulista de Educação Física, São Paulo, v.16, n.2, p.130-43, 2002a.

O atleta e o mito do herói. São Paulo: Casa do Psicólogo, 2001.

O trabalho do atleta e a produção do espetáculo esportivo. Scripta Nova: Revista Eletrónica de Geografia y

Ciências Sociales, Barcelona, v.6, n.119, 2002b. Disponível em: < http://www.ub.es/geocrit/sn/sn119-95.htm>.

SAGRAVE, J.O. Toward a definition of Olympism. In: SAGRAVE, J.O.; CHU, D.B. (Eds.). The Olympic Games in transition. Champaign: Human Kinetics, 1988.

SALVADOR, J.L. El deporte em Occidente: historia, cultura y política. Madrid: Cátedra, 2004.

SEVCENKO, N. A corrida para o século XXI: no loop da montanha russa. São Paulo: Companhia das Letras, 2001.

SIMONS, V.; JENNINGS, A. Los señores de los anillos. Barcelona: Ediciones Transparência, 1992.

TAVARES, O. Esporte, movimento olímpico e democracia: o atleta como mediador. 2003. Tese (Doutorado - Programa de Pós-graduação em Educação Física) - Universidade Gama Filho, Rio de Janeiro, 2003.

TAVARES, O.A. Referenciais teóricos para o conceito de Olimpismo. In: TAVARES, O.; DaCOSTA, L.P. (Eds.). Estudos olímpicos. Rio de Janeiro: Gama Filho, 1999.

VALENTE, E.F. Notas para uma crítica do Olimpismo. In: TAVARES, O.; DaCOSTA, L.P. (Eds.). Estudos olímpicos. Rio de Janeiro: Gama Filho, 1999.

VERNANT, J.P. Mito e pensamento entre os gregos. Rio de Janeiro: Paz e Terra, 1990.

YALOURIS, N. The olympic games in Ancient Greece. Athens: Athenon, 2003.

WALSH, A.; GIULIANOTTI, R. Moral philosophy out on the track: what might be done? In: McNAMEE, M. (Ed.). The ethics of sports. New York: Routledge, 2010.

Ethics, money and sport. London: Routledge, 2007.

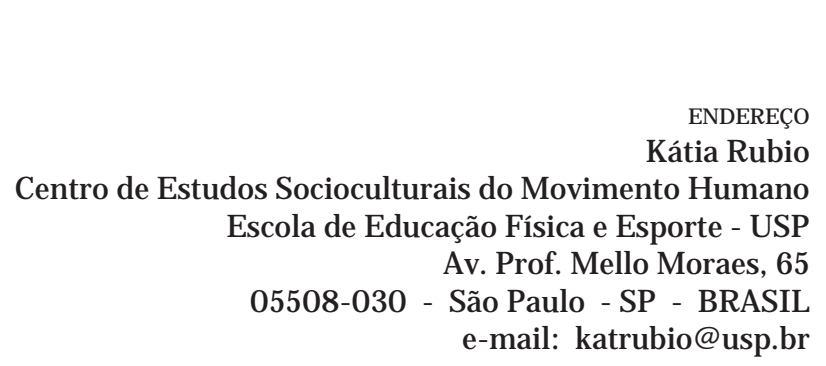

90 • Rev. bras. Educ. Fís. Esporte, São Paulo, v.25, p.83-90, dez. 2011 N. esp. 